\title{
Intrapartum Perinatal Mortality
}

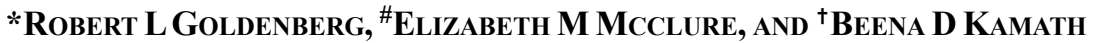 \\ ${ }^{*}$ Drexel University, Philadelphia, USA, ${ }^{\#}$ Research Triangle Institute, North Carolina, USA, and ${ }^{\dagger}$ Cincinnati Children's Hospital \\ Medical Center, Ohio, USA. Correspondence to: Robert L Goldenberg; rgoldenb@drexelmed.edu
}

I ntrapartum perinatal mortality, the deaths that occur during the period around birth, is a major problem in developing countries accounting for more than one million stillbirths and a similar number of neonatal deaths worldwide each year [1,2]. A number of authors have emphasized that the time encompassing labor and the 24 hours after birth is the most dangerous period for both the mother and fetus/neonate [3]. To begin to focus attention on these deaths, several authors have created a new measure of pregnancy outcome-the sum of intrapartum stillbirths and early neonatal deaths $>2500 \mathrm{~g}$, with the denominator all births $>2500 \mathrm{~g}$ [4]. This measure, which considers mortality to fetuses alive on admission to the health facility (often determined by Doptone) through discharge of the neonate, typically at 6 or 12 hours of age, is an important concept, since it is only during this time period that care in the facility can influence the outcome. By eliminating births likely to be preterm, this measure should count only those births with a reasonable likelihood of survival - if the obstetric and early neonatal care were good. As such, some authors have advocated using this measure as an indicator of the quality of obstetric care $[4,5]$. In the study reported here, the authors have included fresh stillbirth as a surrogate for an intrapartum fetal death and only asphyxia-related neonatal deaths instead of all early neonatal deaths [6]. Considering only births occurring at $>35$ weeks or $>2000 \mathrm{~g}$ is also similar to the proposed indicator which only counts births of $2500 \mathrm{~g}$ or more. Thus, we believe the authors have developed an appropriate outcome to measure the quality of intrapartum care [6].

We have been impressed that the same obstetric conditions that kill mothers are also responsible for most of the stillbirths and many of the neonatal deaths as well [7]. These conditions include preeclampsia/eclampsia, obstructed labor and the associated infection and hemorrhage, obstetric hemorrhage from other causes and especially abruption, as well as obstetric risk factors such as growth restriction, fetal distress, malpositions, and multiple pregnancies. We emphasize that most of the precursors of stillbirth and many of the precursors of neonatal asphyxia are obstetric in origin.

From our perspective, there are two ways to reduce the mortality and long term morbidity associated with asphyxia. One is to treat the asphyxiated infant in the postpartum period through a combination of neonatal resuscitation, ventilation and other supportive measures. However, potentially more important, is the prevention of antenatal and intrapartum asphyxia in the first place. Appropriate obstetrical care, both in the prenatal but especially in the intrapartum period, is crucial to reduce intrapartum stillbirth and neonatal asphyxia. For example, regular screening of all women in the antepartum period for preeclampsia with blood pressure measurements, with an appropriately timed delivery, can prevent progression to severe preeclampsia/eclampsia. Since most cases of eclampsia occur at or near term, an indicated delivery should reduce both stillbirth and neonatal asphyxia without significantly increasing neonatal deaths from prematurity. Similarly, screening for fetal growth restriction with delivery close to term will have similar results. Close monitoring and appropriate care during labor to enable obstetrical providers to recognize conditions such as prolonged labor, placental abruption, placental previa, fetal malposition, and fetal distress, can allow for rapid intervention with cesarean section, to further reduce rates of stillbirth and neonatal asphyxia.

Reducing perinatal asphyxia on a population basis requires a heath system in which every woman is screened for the conditions discussed above and is provided care for those conditions in a timely fashion. Since many of the conditions progress rapidly during labor, advanced planning for the treatment is often helpful. Regular obstetric drills for conditions like eclampsia, severe hemorrhage, and fetal distress will allow the staff to practice for these emergency conditions, and make sure that when presented with these conditions, there are adequate equipment, medications and trained staff available so that both the mother and fetus are 
delivered safely. Perinatal death audits that evaluate both cause of death and potential for preventability are crucial to reduce preventable mortality. Finally, availability of sufficient staff and appropriate equipment to handle obstetric emergencies is crucial. Most important is the recognition that in order to reduce neonatal death and disability from intrapartum asphyxia, prevention and treatment of obstetrical conditions in the mother is better than resuscitation of an already asphyxiated infant. This paper is important because it focuses on the intrapartum factors related to perinatal asphyxia, and starts to address preventable causes [6]. Further work should evaluate methods to reduce perinatal asphyxia of obstetric origin.

Funding: RLG and EMM received support from the NICHD Global Network for Women's and Children's Health Research. RLG, EMM and BDK received support from the Bill and Melinda Gates Foundation's Mandate Project.

Competing interests: None stated.

\section{REFERENCES}

1. Cousens S, Blencowe H, Stanton C, Chou D, Ahmed S, Steinhardt L, et al. National, regional, and worldwide estimates of stillbirth rates in 2009 with trends since 1995 : a systematic analysis. Lancet. 2011;377:1319-30.

2. Lozano R, Wang H, Foreman KJ, Rajaratnam JK, Naghavi $\mathrm{M}$, Marcus JR, et al. Progress towards millennium development goals 4 and 5 on maternal and child mortality: an updated systematic analysis. Lancet. 2011;378:1139-65.

3. Bhutta ZA, Darmstadt GL, Haws RA, Yakoob MY, Lawn JE. Delivering interventions to reduce the global burden of stillbirths: improving service supply and community demand. BMC Pregnancy Childbirth. 2009;9 Suppl 1:S7.

4. Fauveau V. New indicator of quality of emergency obstetric and newborn care. Lancet. 2007;370:1310.

5. McClure EM, Goldenberg RL, Bann CM. Maternal mortality, stillbirth and measures of obstetric care in developing and developed countries. Int J Gynaecol Obstet. 2007;96:139-46.

6. Rani S, Chawla D, Huria A, Jain S. Risk factors for perinatal mortality due to asphyxia among emergency obstetric referrals in a tertiary hospital. Indian Pediatr. 2012; 49:191-4.

7. Goldenberg RL, McClure EM, Bhutta ZA, Belizán JM, Reddy UM, Rubens CE, et al. Stillbirth: the vision for 2020. Lancet. 2011;377:1798-805.

\title{
Maternal Risk Factors Affecting Perinatal Mortality
}

\author{
NeERJa Goel ANd Bindiya GuPTA \\ Department of Obstetrics and Gynaecology, University College of Medical Sciences and \\ Guru Tegh Bahadur Hospital, Delhi 110095. Correspondence to: Dr Neerja Goel; neerjagoel2002@yahoo.com
}

$\mathrm{T}$ The term "perinatal mortality" includes deaths that are attributed to obstetric events, such as stillbirths and neonatal deaths in the first week of life. Perinatal mortality is an important indicator of maternal care, health and nutrition; it also reflects the quality of obstetric and pediatric care available. The vast majority of global perinatal deaths occur in the low- and middle-income countries. The perinatal mortality and stillbirth rates for India according to National Family Health Survey-3 (2005-06) are 48.5 per 1000 live births and 19.2 per 1000 pregnancies, respectively [1].

Stillbirths include intrauterine fetal deaths which occur prior to the onset of labor (antepartum stillbirths) as well as those that occur during labor (intrapartum stillbirths). Antepartum stillbirths are caused by maternal risk factors like hypertensive disorders, placental dysfunction, hemorrhage, and fetal or placental abnormalities, which predispose the fetus to intra-uterine hypoxia and/or infection. In a recent meta-analysis, several interventions showed clear evidence of impact of interventions such as heparin therapy for certain maternal indications, syphilis screening and treatment, and insecticide-treated bed nets for prevention of malaria, on reduction of stillbirths [2]. Other interventions, such as management of obstetric intrahepatic cholestasis, maternal anti-helminthic treatment, and intermittent preventive treatment of malaria, showed promising impact on stillbirth rates but require confirmatory studies [2]. As of now interventions like antibiotics in prolonged premature rupture of membranes, anti-oxidant supplementation for deficient mothers, calcium supplementation to prevent PIH and preeclampsia in deficient populations, periodontal care for mothers as well cessation of smoking by pregnant females and reduction of exposure to smokeless tobacco have no definite impact on reduction of stillbirth or perinatal mortality rates. Protein-energy malnutrition and lack of 
peri-conceptional folic acid, have yet not shown significant associated reductions in stillbirth rates [2].

In this issue of Indian Pediatrics, a study from a teaching hospital in North India evaluated the clinical, behavioral and health-care associated risk factors of intrapartum perinatal mortality (IPPM) [3]. They reported that a large proportion of women deliver at home or reach health facilities late during labor. In addition, limited round-the-clock coverage, lack of trained health care personnel and non-adherence to standard management protocols contributed to increased IPPM. Low socioeconomic status, absence of hemoglobin and urine examination during pregnancy, obstructed labor, and a delay in seeking health care were significant risk factors for intrapartum-related perinatal mortality among emergency obstetric referrals [3]. The mode of delivery did not affect the IPPM; previously, timely delivery, often by caesarean section or instrumental vaginal delivery, has been shown to reduce associated intrapartum stillbirth, and has been credited for the relatively low intrapartum stillbirth rates in high-income countries. A recent meta-analysis, outlined the clear advantage of strategies like comprehensive emergency obstetric care packages, including caesarean section in breech delivery, and induction of labor ( $v s$ expectant treatment) in post-term pregnancy. Other advanced interventions such as amnioinfusion and hyperoxygenation need further evidence before their use can be advocated as a policy [5]. A number of studies have shown that suboptimal care, particularly inadequate, inappropriate, or delayed care of complications such as obvious fetal distress, placental abruption, breech presentation, twin pregnancy, or eclampsia, is associated with increased perinatal mortality [6].

While most of the success stories on reduction in perinatal mortality are in relation to developed countries and mostly in term babies, a lot needs to be desired in resource-poor countries where further research is still needed to decrease the alarmingly high rates of perinatal mortality and to define more appropriate interventions.

Competing interests: None stated; Funding: Nil.

\section{REFERENCES}

1. National Family Health Survey-3: Summary of findings. Available from: http://www.nfhsindia.org/NFHS3\%20Data/VOL-1/Summary\%20of\%20Findings $\% 20$ (6868K).pdf. Accessed on October 13, 2011.

2. Menezes EV, Yakoob MY, Soomro T, Haws RA, Darmstadt GL, Bhutta ZA. Reducing stillbirths: prevention and management of medical disorders and infections during pregnancy. BMC Pregnancy Childbirth. 2009;9 (Suppl 1):S4.

3. Rani S, Chawla D, Huria A, Jain S. Risk factors for perinatal mortality due to asphyxia among emergency obstetric referrals in a tertiary hospital. Indian Pediatr. 2012;49:191-4.

4. Goldenberg RL, McClure EM, Bann CM. The relationship of intrapartum and antepartum stillbirth rates to measures of obstetric care in developed and developing countries. Acta Obstet Gynecol Scand. 2007;86:1303-9.

5. Darmstadt GL, Yakoob MY, Haws RA, Menezes EV, Soomro T, Bhutta ZA. Reducing stillbirths: interventions during labour. BMC Pregnancy Childbirth. 2009;9 (Suppl 1):S6.

6. Gaffney G, Sellers S, Flavell V, Squier M, Johnson A. Case-control study of intrapartum care, cerebral palsy, and perinatal death. BMJ. 1994;308:743-50.

\title{
T-cells and Cardiac Complications in Infectious Mononucleosis
}

\author{
Debbie van BaARle \\ Deparment of Internal Medicine and Infectious Diseases, and Department of Immunology, University Medical Center Utrecht, \\ Lundlaan 6, 3584EA Utrecht, Netherlands.d.vanbaarle@umcutrecht.nl
}

I nfectious mononucleosis (IM) is characterized by symptoms which are thought to be caused by -either directly or indirectly-the expansion of $\mathrm{CD} 3+\mathrm{CD} 8+$ T-cells after acute Epstein-Barr virus-infection resulting in a decreased CD4/CD8 ratio. Over $50 \%$ of the T-lymphocytes response may be EBVspecific [1,2]. Several viral infections (coxsackie B3, influenza, parvovirus B19, varicella-zoster, cytomegalovirus) have been described to be associated with cardiac complications, including pericarditis, myocarditis and pericardial effusion [3-5]. However, there is not much known about the involvement of cardiac complications in EBV-induced IM, except for a few case studies. The study by Papadopoulou, et al., [6]in this issue of Indian Pediatrics for the first time sets out to analyze the occurrence of cardiac complications in infectious mononucleosis in a systematic manner. They evaluated 25 children suffering from IM during the acute phase of infection and after 3-6 months for cardiac complications and relate these cardiac complications to $\mathrm{CD} 3+\mathrm{CD} 8+\mathrm{T}$ 
cell counts and CD4/CD8 ratio's. As anticipated, the study showed that $\mathrm{CD} 3+\mathrm{CD} 8+\mathrm{T}$-lymphocytes were increased and CD4/CD8 ratios were decreased in all IM patients. Interestingly, echocardiography revealed mild pericardial effusion in 13/25 patients, of which $12 \mathrm{had}$ very low $\mathrm{CD} 4 / \mathrm{CD} 8$ ratios. In most patients all abnormal lymphocyte populations returned to normal within 6 months as did any cardiac complication. Interestingly, persistence of mild pericardial effusion was seen in five patients. In these children $\mathrm{CD} 3+\mathrm{CD} 8+\mathrm{T}$ cells were elevated and $\mathrm{CD} 4 / \mathrm{CD} 8$ ratios were decreased.

Although one of the difficulties in performing these kind of studies lies in identifying symptomatic EBVinfections, as the symptoms are mostly non-specific, the authors analyzed EBV seroconversion data and performed T-cell phenotyping, making the diagnosis of infectious mononucleosis more straightforward and therefore patient selection was done properly. Although the authors did a great job in performing this study and linking the cardiac complications to T-cell counts, they could have discussed the mechanism behind the occurrence of these cardiac complications better and include discussion on other viruses which have previously been implicated in the context of cardiac symptoms. The authors try to link the high T-cell numbers to the cardiac complications, but state that this could be the result of high load. Unfortunately, no attempt was made to actually measure the viral load to elucidate this.

So the question remains whether cardiac complications are caused by direct cytopathic actions of the virus or by virus-initiated autoimmunity of the expanded T cells [7]. Seko, et al., [8] showed restricted usage of T-cell receptor Valpha-V beta genes in infiltrating cells in the hearts of patients with acute myocarditis and dilated cardio-myopathy, suggesting that an antigen-specific T-cell subset plays a role. In addition, autoimmune effects are suggested as the underlying mechanism for myocardial cellular destruction and ventricular dysfunction in children following infection with varicella zoster virus [8]. The involvement of T-cells was also implicated in an experimental myocarditis model in mice after infection with influenza A virus. It was shown that not the virus directly, but some function of the host against viral evasion mediated myocarditis as it was abolished by X-irradiation. As myocarditits did not develop in congenitally athymic nude mice suggests that T-cells play a critical role in the development of myocarditis [9]. As the EBV-specific T-cells at the acute phase are characterized by lack of expression of CD27 indicative of high effector function [10], it may well be that these T-cells are involved in cardiac complications.
Additional studies are required to prove this.

Although the context of the study by Papadopoulou, et al was less clear and the link to autoimmunity effects could have been discussed, at least their paper suggests that very low $\mathrm{CD} 4 / \mathrm{CD} 8$ ratio may be taken as a surrogate marker for pericardial effusion and increased CD3+CD8+ T-cells after 3 months are associated with persistence of pericardial effusion and may thereby identify patients at continuous risk. Additional analyses are required to establish cutoff values of T-cell phenotypes for cardiac complications.

Competing interests: None stated; Funding: Nil

\section{REFERENCES}

1. Callan MF, Tan L, Annels N, Ogg GS, Wilson JD, O'Callaghan CA, et al. Direct visualization of antigenspecific CD8+ T cells during the primary immune response to Epstein-Barr virus In vivo. J Exp Med. 1998;187:13951402 .

2. Williams H, Macsween K, McAulay K, Higgins C, Harrison $\mathrm{N}$, Swerdlow A, et al. Analysis of immune activation and clinical events in acute infectious mononucleosis. J Infect Dis. 2004; 190:63-71.

3. Gross ER, Gander JW, Reichstein A, Cowles RA, Stolar CJ, Middlesworth W. Fulminant pH1N1-09 influenzaassociated myocarditis in pediatric patients. Pediatr Crit Care Med. 2011;12:e99-101.

4. Abrams D, Derrick G, Penny DJ, Shinebourne EA, Redington AN. Cardiac complications in children following infection with varicella zoster virus. Cardiol Young. 2001;11:647-52.

5. Wu CT, Huang JL. Pericarditis with massive pericardial effusion in a cytomegalovirus-infected infant. Acta Cardiol. 2009;64:669-71.

6. Papadopoulou-Legbelou K, Papadopoulou-Alataki E, Fleva A, Spanou S, Pavlitou A, Varlamis G. Cardiac Complications and immunophenotypic profile of infectious mononucleosis syndrome in children. Indian Pediatr.2012;49:195-8.

7. Leslie K, Blay R, Haisch C, Lodge A, Weller A, Huber S. Clinical andexperimental aspects of viral myocarditis. Clin Microbiol Rev. 1989;2:191-203.

8. Seko Y, Ishiyama S, Nishikawa T, Kasajima T, Hiroe M, Kagawa N et al. Restricted usage of T cell receptor Valpha$\mathrm{V}$ beta genes in infiltrating cells in the hearts of patients with acute myocarditis and dilated cardiomyopathy. J Clin Invest. 1995;96:1035-41.

9. Sakamoto M, Suzuki F, Arai S, Takishima T, Ishida N. Experimental myocarditis induced in mice by infection with influenza A2 virus. Microbiol Immunol.1981;25: 173-81.

10. Scherrenburg J, Piriou ER, Nanlohy NM, van Baarle D. Detailed analysis of Epstein-Barr virus-specific CD4+ and CD8+ T cell responses during infectious mononucleosis. Clin Exp Immunol. 2008;153:231-9. 